\title{
Significance of bile culture surveillance for postoperative management of pancreatoduodenectomy
}

\author{
Keishi Sugimachi ${ }^{1 *} \mathbb{D}$, Tomohiro Iguchi', Yohei Mano ${ }^{1}$, Masaru Morita ${ }^{2}$, Masaki Mori $^{3}$ and Yasushi Toh $^{2}$
}

\begin{abstract}
Background: The management of infectious complications is important in pancreatoduodenectomy (PD). We sought to determine the significance of preoperative surveillance bile culture in perioperative management of PD.

Methods: This study enrolled 69 patients who underwent PD for malignant tumors at a single institute between 2014 and 2017. Surveillance bile culture was performed before or during surgery. Correlations between the incidence of infectious postoperative complications and clinicopathological parameters, including bile cultures, were evaluated.

Results: Preoperative positive bile culture was confirmed in 28 of 51 patients (55\%). Bile culture was positive in 27 of 30 cases (90\%) with preoperative biliary drainage, and 1 of 21 cases $(5 \%)$ without drainage $(p<0.01)$.

Preoperative isolated microorganisms in bile were consistent with those detected in surgical sites in 11 of 27 cases (41\%). Cases with positive multi-drug-resistant bacteria in preoperative bile culture showed significantly higher incisional SSI after PD $(p=0.01)$. The risk factors for the incidence of organ/space SSI were soft pancreatic texture ( $p$ $=0.01)$ and smoking history $(p=0.02)$ by multivariate analysis. Preoperative positive bile culture was neither associated with organ/space SSI nor overall postoperative complications.
\end{abstract}

Conclusions: Preoperative surveillance bile culture is useful for the management of wound infection, prediction of causative pathogens for infectious complications, and the selection of perioperative antibiotic prophylaxis.

Keywords: Bile culture, Pancreatoduodenectomy, Surgical site infection, Multi-drug resistance

\section{Background}

Pancreatoduodenectomy (PD) is the only curative option for pancreatic, biliary, and duodenal malignant tumors. Perioperative management of patients undergoing PD has been dramatically improved in past few decades, but the morbidity still ranges from 20 to $50 \%[1,2]$. The complication and death rates of PD mainly depend on major infectious complications, including postoperative pancreatic fistula (POPF) and biliary leakage, and many other host factors, such as infection, the severity of jaundice, nutritional status, and impaired organ functions $[3,4]$.

Obstructive jaundice is the most common symptom for periampullary and ampullary tumors that need PD; thus,

\footnotetext{
* Correspondence: ksugi@surg2.med.kyushu-u.ac.jp

${ }^{1}$ Department of Hepatobiliary-Pancreatic Surgery, National Hospital Organization Kyushu Cancer Center, 3-1-1 Notame, Minami-ku, Fukuoka 811-1395, Japan

Full list of author information is available at the end of the article
}

biliary drainage has been commonly performed. Preoperative biliary drainage re-establishes entero-hepatic circulation, provides symptomatic relief to patients with pruritus and cholangitis, and serves as a temporizing measure if surgery is delayed or neoadjuvant therapy is considered [5]. However, controversy remains about the pre-operative management of obstructive jaundice undergoing planned $\mathrm{PD}$, because bacterobilia induced by biliary drainage has been reported to be associated with postoperative infectious complication and also even triggers the development of POPF [6-9]. Several studies reported the importance of specific prophylaxes based on bile culture to prevent postoperative complications, but preoperative antibiotics could potentially induce colonization of multi-drug-resistant (MDR) pathogens in the biliary tract $[10,11]$. Though both claims related to biliary drainage may be logically

(C) The Author(s). 2019 Open Access This article is distributed under the terms of the Creative Commons Attribution 4.0 International License (http://creativecommons.org/licenses/by/4.0/), which permits unrestricted use, distribution, and reproduction in any medium, provided you give appropriate credit to the original author(s) and the source, provide a link to the Creative Commons license, and indicate if changes were made. The Creative Commons Public Domain Dedication waiver (http://creativecommons.org/publicdomain/zero/1.0/) applies to the data made available in this article, unless otherwise stated. 
correct, it is important to care and strictly manage biliary infection before PD.

To establish effective and safe strategies for prophylaxis of perioperative infectious complication, more accurate information on the incidence of perioperative biliary infection in patients who have undergone PD is needed. Therefore, we conducted a retrospective study of surveillance bile culture to analyze recent trends and significance of biliary infection on the perioperative outcome of PD.

\section{Methods \\ Patients}

A retrospective cohort study was performed with 69 consecutive patients who underwent PD at a single institute (Kyushu Cancer Center) between the years 2014 and 2017. Data from all these patients were collected from medical charts and analyzed. The demographic data of patients are summarized in Table 1 .

\section{Perioperative management}

Preoperative biliary drainage was performed in 34 of 69 patients (49\%). Endoscopic retrograde (internal) biliary drainage was done in 30 cases $(43 \%)$, endoscopic nasobiliary drainage was done in 2 cases (2\%), and percutaneous transhepatic biliary drainage was done in 2 cases (2\%). Patients treated with antimicrobial agents for high fever or abnormal liver function tests were diagnosed as cholangitis. As a surveillance bile culture, bile specimens were collected at the time of either preoperative biliary drainage procedure or surgery. Multi-drug-resistant pathogens were defined as described elsewhere [12, 13].

Table 1 Demographics and clinical characteristics of the study population

\begin{tabular}{lll}
\hline Factor & Number \\
\hline Sex & Male/female & $45 / 24$ \\
Age & $\begin{array}{l}\text { years } \\
\text { Dancrease } \\
\text { duct tumor/duodenal } \\
\text { tumor }\end{array}$ & $67.3 \pm 9.9$ \\
& $\begin{array}{l}\text { Current } \\
\text { (never or ever) }\end{array}$ & $17(24.6 \%)$ \\
Smoking history & & $22.3 \pm 2.9$ \\
Body mass index & $22(31.9 \%)$ \\
$\begin{array}{l}\text { Diabetes mellitus } \\
\begin{array}{l}\text { Preoperative biliary } \\
\text { stent placement } \\
\text { Surgical procedure }\end{array}\end{array}$ & $34(49.3 \%)$ \\
$\begin{array}{l}\text { Episode of preoperative } \\
\text { cholangitis }\end{array}$ & PD/PPPD/SSPPD & $11 / 8 / 50$ \\
\hline
\end{tabular}

Abbreviations: $P D$ pancreatoduodenectomy, $P P P D$ pylorus preserving pancreatoduodenectomy, SSPPD subtotal stomach preserving pancreatoduodenectomy
The child method was applied for the reconstruction of PD. An internal or external stent was placed at pancreatojejunostomy, and the abdominal cavity was routinely drained using closed suction tubes in all patients. Second-generation cephalosporins were used as prophylactic antibiotics for all patients at least 2 days after operation without regard to the preoperative bile culture.

All infectious complications were proven by a positive culture of purulent discharge. POPF was defined according to the International Study Group of Pancreatic Fistula [14], and the grade of complication was defined by Clavien-Dindo classification [15].

\section{Statistical analysis}

All statistical analyses were performed using JMP 13.0 software (SAS; Cary, NC, USA). All variables were expressed as the mean \pm standard deviation. Continuous variables were compared using the Mann-Whitney $U$ test. Categorical data were compared using the $\chi^{2}$ test. Logistic regression analysis was performed to identify the independent predictors of complications. A $p$ value of $<0.05$ was regarded as statistically significant.

\section{Results}

Pre- and intra-operative surveillance bile culture

Preoperative and intraoperative bile culture was performed in 12 (17\%) and 46 patients (67\%), respectively. Both pre- and intra-operative bile culture were done in 7 patients; thus, surveillance bile culture was done in 51 patients $(74 \%)$ overall. Bile culture was positive in 28 of 51 patients (55\%), and MDR pathogens were detected in 11 of 51 patients (22\%). In 7 patients, those both pre- and intra-operative bile culture were done, the bile culture was positive at preoperative drainage in 4 cases and became positive after drainage (intraoperatively) in 3 cases. In 3 of 4 cases, the MDR pathogens matched between preoperative and intraoperative cultures. Detected MDR pathogens were Enterobacter species in 7, methicillin-resistant Staphylococcus aureus in 2, Pseudomonas species in 1, and extended spectrum $\beta$-lactamase-producing strains in 1 case. Bile culture was positive in 27 of 30 cases $(90 \%)$ with preoperative biliary drainage, and 1 of 21 cases (5\%) without drainage with statistically significant difference $(p<$ $0.01)$. All 11 patients those MDR pathogens were detected had undergone biliary drainage. MDR pathogens were detected by preoperative culture in 2 patients, intraoperative culture in 8 patients, and both in 1 patient.

\section{Postoperative complications}

Relationship between surveillance bile culture and postoperative complications was analyzed in 51 cases those surveillance bile culture was done (Table 2). Incisional and organ/space surgical site infection (SSI) occurred in 6 (12\%) and $33(65 \%)$ cases, respectively. The occurrence 
Table 2 Postoperative complications and surveillance bile culture

\begin{tabular}{|c|c|c|c|c|c|}
\hline Complication & $\begin{array}{l}\text { All cases } \\
(n=51)\end{array}$ & $\begin{array}{l}\text { Bile culture positive } \\
(n=28)\end{array}$ & $p$ value & $\begin{array}{l}\text { MDR pathogens positive } \\
(n=11)\end{array}$ & $p$ value \\
\hline Incisional SSI (\%) & $6(12)$ & $4(14)$ & 0.53 & $4(36)$ & 0.01 \\
\hline Organ/space SSI (\%) & $33(65)$ & $18(64)$ & 0.95 & $7(63)$ & 0.93 \\
\hline Bile leakage (\%) & $4(8)$ & $2(7)$ & 0.84 & $1(9)$ & 0.86 \\
\hline Pancreatic fistula (\%) & $21(41)$ & $12(43)$ & 0.79 & $4(36)$ & 0.71 \\
\hline Cholangitis (\%) & $3(6)$ & $2(7)$ & 0.67 & $1(9)$ & 0.63 \\
\hline Enteritis (\%) & $3(6)$ & $2(7)$ & 0.67 & $1(9)$ & 0.63 \\
\hline Clavien-Dindo $\geq 3$ complication (\%) & $16(31)$ & $7(25)$ & 0.28 & $3(27)$ & 0.74 \\
\hline
\end{tabular}

Abbreviations: SSI surgical site infection, MDR multi-drug resistance

of incisional SSI was significantly higher in the cases with MDR pathogen positive in bile culture $(p=0.01)$. There was no significant correlation between the morbidity of organ/space SSI and surveillance bile culture.

\section{Coincidence of pre-operative bile culture and post-operative abdominal fluid culture}

Bile cultures were postoperatively obtained only in 7 cases because external biliary drainage was not applied in most cases. In the postoperative course, the culture of abdominal fluid from intra-abdominal drains was obtained from 54 of the 69 patients. The results of preoperative bile culture and postoperative abdominal fluid culture were compared. The postoperative culture was positive in 37 cases (68\%), and MDR pathogens were positive in 23 cases (43\%). Both pre- and post-operative cultures were obtained in 48 cases. The coincidence of pre- and postoperative culture was examined in 26 cases, and those preoperative bile cultures were positive. The coincidence of pathogens was observed in 11 cases (42\%) (Table 3), and 10 out of these 11 cases, the detected bacteria were causative pathogens of SSI. In 10 cases of MDR pathogen testing positive in preoperative bile culture, $8(80 \%)$ showed the same pathogens in abdominal fluid postoperatively, and the rate of coincidence of detected pathogens was significantly higher in cases with MDR-positive compared to non MDR-positive ( $p$ $<0.01$, Table 3). Detected MDR pathogens were Enterobacter species in 5, methicillin-resistant Staphylococcus aureus in 2, and Pseudomonas species in 1 case.

Table 3 Coincidence of pathogens in preoperative and postoperative culture

\begin{tabular}{llll}
\hline Culture & $\begin{array}{l}\text { Coincidence of } \\
\text { pathogens } \\
(n=11)\end{array}$ & $\begin{array}{l}\text { Non-coincidence } \\
\text { of pathogens } \\
(n=15)\end{array}$ & $p$ value \\
\hline $\begin{array}{l}\text { Drug sensitive pathogen } \\
\text { positive }(n=16)\end{array}$ & $3(19 \%)$ & $13(81 \%)$ & $<0.01$ \\
$\begin{array}{l}\text { Multi-drug resistant } \\
\text { pathogen positive } \\
(n=10)\end{array}$ & $8(80 \%)$ & $2(20 \%)$ & \\
\hline
\end{tabular}

Risk factors associated with morbidity of organ/space SSI

Risk factors associated with morbidity of organ/space SSI were analyzed. In univariate analysis, diagnosis of pancreatic adenocarcinoma, operative time $\geq 360 \mathrm{~min}$, blood loss $\geq 400 \mathrm{~g}$, soft pancreatic texture, and main pancreatic duct diameter $\leq 3 \mathrm{~mm}$ were the risk factors of occurrence of organ/space SSI (Table 4). In multivariate analysis, smoking history and pancreatic texture were the independent risk factors associated with organ/space SSI (Table 4). The preoperative bile culture was not statistically associated with the occurrence of organ/ space SSI.

\section{Discussion}

We have shown that bacterobilia is induced by preoperative biliary obstruction and drainage and associated with higher incidence of incisional SSI. The coincidence of pathogens, especially MDR, between bile and post-operative infectious lesions, such as intraabdominal fluid, were frequently observed in our series. These results indicated that colonization in bile due to pre-operative biliary drainage could be causative pathogens of postoperative infectious complications.

Postoperative pancreatic fistula is a major determinant of postoperative infectious complications, and it is associated with mortality of PD. Thus, the management of infectious complications is critical in perioperative care $[16,17]$. Our multivariate analysis indicated that bacterobilia is not an independent risk factor for organ/space SSI, but pancreatic texture and smoking history were associated with the incidence of SSI. Those results were also observed by the analysis of 51 cases those surveillance bile culture was done (data not shown). Soft pancreatic parenchyma and small pancreatic duct diameter are a well-established risk factor of POPF [18, 19], and our present data also indicated that risk factors for POPF are dominant compared with bacterobilia in the incidence of organ/space SSI.

The present data, consistent with the literature, showed that preoperative biliary drainage caused bacterobilia [6] Benefits of preoperative biliary drainage for patients 
Table 4 Risk factors associated with morbidity of organ/space surgical site infection

\begin{tabular}{|c|c|c|c|c|c|c|}
\hline \multirow[t]{2}{*}{ Factors } & & \multicolumn{3}{|c|}{ Univariate analysis } & \multicolumn{2}{|l|}{ Multivariate analysis } \\
\hline & & OSSI(-) $n=26$ & oSSI(+) $n=43$ & $p$ value & hazard ratio $(95 \% \mathrm{Cl})$ & $p$ value \\
\hline Diagnosis & PDAC/others & $20 / 6$ & $20 / 23$ & 0.01 & & \\
\hline Smoking history & $(+) /(-)$ & $4 / 22$ & $13 / 30$ & 0.16 & $32.7(1.65-647)$ & 0.02 \\
\hline Operative time (min) & $\geq 360 / \leq 359$ & $13 / 13$ & $32 / 11$ & 0.04 & & \\
\hline Blood loss (g) & $\geq 400 / \leq 399$ & $16 / 10$ & $14 / 29$ & 0.02 & & \\
\hline Pancreatic texture & Soft/hard & $5 / 21$ & $31 / 11$ & $<0.01$ & $17.2(1.77-168)$ & 0.01 \\
\hline $\begin{array}{l}\text { Main pancreatic duct } \\
\text { diameter }(\mathrm{mm})\end{array}$ & $\leq 3 / \geq 4$ & $9 / 17$ & $26 / 13$ & 0.01 & & \\
\hline Preoperative bile culture & Positive/negative & $10 / 16$ & $18 / 25$ & 0.78 & & \\
\hline $\begin{array}{l}\text { Drug resistant pathogen } \\
\text { in preoperative bile culture }\end{array}$ & Positive/negative & $4 / 22$ & $7 / 36$ & 0.92 & & \\
\hline
\end{tabular}

Abbreviations: PDAC pancreatic adenocarcinoma, oSSI organ/space surgical site infection, $\mathrm{Cl}$ confident interval

undergoing PD remain largely controversial [7, 20-22]. Several studies question its value given morbidity and complications associated with biliary infection. However, decreased jaundice can relieve patient symptom and improve immunonutritious conditions through entero-hepatic circulation [23]. More importantly, neoadjuvant preoperative chemotherapy is becoming more common for borderline resectable pancreatic adenocarcinoma; thus, preoperative biliary drainage is essential for at least certain patient groups [24]. Our study indicated that the most serious complications mainly depend on the risk factors of POPF, but not on bacterobilia; thus, biliary drainage is acceptable if necessary. In cases with biliary drainage, it is important to apply strict management to prevent infectious post-operative complications. We recommend the use of specific antibiotics based on surveillance bile culture to avoid colonization of MDR bacteria and to manage surgical incisions as contaminated wounds. Our study supports the theory reported by Okamura et al. that preoperative bile culture-target prophylactic antibiotics decreased SSI following hepato-pancreato-biliary surgery [25].

We acknowledge limitations of this non-randomized study, including relatively small sample size. Many studies reported that bile is contaminated in patients undergoing PD after biliary drainage [6-10, 20, 21]. Our study agrees with the importance of surveillance bile culture for management of patients with PD. The present study described the impact of bacterobilia caused by MDR pathogens, which is becoming more important with the current spread of antibiotic-resistant bacteria, not only in bile but in postoperative infectious lesions.

\section{Conclusions}

Higher incidence of incisional SSI is anticipated in patients undergoing PD with biliary drainage due to bacterobilia. Management of wounds as contaminated and use of appropriate prophylactic antimicrobial agents based on surveillance bile culture are needed to improve operative outcomes.

\section{Abbreviations}

MDR: Multi-drug resistant; PD: Pancreatoduodenectomy; POPF: Postoperative pancreatic fistula; SSI: Surgical site infection

\section{Acknowledgements}

The authors thank Drs. Tomonori Nakanoko, Hideo Uehara, Masahiko Sugiyama, Mitsuhiko Ohta, and Masahiko Ikebe for their contribution to the clinical data collection. The also authors thank Ms. Ai Ohyama and Ms. Emiko Miyamoto for their technical assistance.

\section{Authors' contributions}

KS and TI conceived and designed the study. KS, TI, and YM contributed to the acquisition, analysis, and interpretation of data. KS and MMorita drafted the manuscript. MMorita, MMori, and YT critically revised the manuscript. All authors read and approved the final manuscript.

\section{Funding}

This work was supported in part by the Uehara Memorial Foundation, Tokyo, Japan.

\section{Availability of data and materials}

All data analyzed during this study are included in this published article.

Ethics approval and consent to participate

The study was approved by the ethics committee of the Kyushu Cancer Center (No. 2019-54).

\section{Consent for publication}

The study was undertaken with the patient's consent.

\section{Competing interests}

The authors declare that they have no competing interests.

\section{Author details}

${ }^{1}$ Department of Hepatobiliary-Pancreatic Surgery, National Hospital Organization Kyushu Cancer Center, 3-1-1 Notame, Minami-ku, Fukuoka 811-1395, Japan. ${ }^{2}$ Department of Gastroenterological Surgery, National Hospital Organization Kyushu Cancer Center, 3-1-1 Notame, Minami-ku, Fukuoka 811-1395, Japan. ${ }^{3}$ Department of Surgery and Science, Graduate School of Medical Sciences, Kyushu University, 3-1-1 Maidashi, Higashi-ku, Fukuoka 812-8582, Japan.

Received: 12 October 2019 Accepted: 19 December 2019 Published online: 30 December 2019

\section{References}

1. Greenblatt DY, Kelly KJ, Rajamanickam V, Wan Y, Hanson T, Rettammel R, Winslow ER, Cho CS, Weber SM. Preoperative factors predict perioperative morbidity and mortality after pancreaticoduodenectomy. Ann Surg Oncol. 2011;18:2126-35. 
2. Gouma DJ, van Geenen RC, van Gulik TM, de Haan RJ, de Wit LT, Busch OR, Obertop H. Rates of complications and death after pancreaticoduodenectomy: risk factors and the impact of hospital volume. Ann Surg. 2000;232:786-95.

3. Shrikhande SV, Sivasanker M, Vollmer CM, Friess $H$, Besselink MG, Fingerhut A, Yeo CJ, Fernandez-delCastillo C, Dervenis C, Halloran C, et al. Pancreatic anastomosis after pancreatoduodenectomy: a position statement by the International Study Group of Pancreatic Surgery (ISGPS). Surgery. 2017;161:1221-34.

4. Sugimachi $K$, Iguchi T, Mano $Y$, Nishijima T, Nakanoko T, Uehara H, Sugiyama M, Ohta M, lkebe M, Morita M, et al. The impact of immunonutritional and physical status on surgical outcome after pancreaticoduodenectomy in elderly Patients. Anticancer Res. 2019;39:6347-53.

5. Sauvanet A, Boher JM, Paye F, Bachellier P, Sa Cuhna A, Le Treut YP, Adham M, Mabrut JY, Chiche L, Delpero JR, French Association of S. Severe jaundice increases early severe morbidity and decreases long-term survival after pancreaticoduodenectomy for pancreatic adenocarcinoma. J Am Coll Surg. 2015;221:380-9.

6. Lee PJ, Podugu A, Wu D, Lee AC, Stevens T, Windsor JA. Preoperative biliary drainage in resectable pancreatic cancer: a systematic review and network meta-analysis. HPB (Oxford). 2018;20:477-86.

7. Mussle B, Hempel S, Kahlert C, Distler M, Weitz J, Welsch T. Prognostic impact of bacterobilia on morbidity and postoperative management after pancreatoduodenectomy: a systematic review and meta-analysis. World J Surg. 2018;42:2951-62.

8. Ohgi K, Sugiura T, Yamamoto Y, Okamura Y, Ito T, Uesaka K. Bacterobilia may trigger the development and severity of pancreatic fistula after pancreatoduodenectomy. Surgery. 2016;160:725-30.

9. Cortes A, Sauvanet A, Bert F, Janny S, Sockeel P, Kianmanesh R, Ponsot P, Ruszniewski P, Belghiti J. Effect of bile contamination on immediate outcomes after pancreaticoduodenectomy for tumor. J Am Coll Surg. 2006;202:93-9.

10. Sudo T, Murakami Y, Uemura K, Hayashidani Y, Hashimoto Y, Ohge H, Sueda T. Specific antibiotic prophylaxis based on bile cultures is required to prevent postoperative infectious complications in pancreatoduodenectomy patients who have undergone preoperative biliary drainage. World J Surg. 2007;31:2230-5.

11. Sugawara G, Yokoyama Y, Ebata T, Igami T, Yamaguchi J, Mizuno T, Yagi T, Nagino M. Preoperative biliary colonization/infection caused by multidrugresistant (MDR) pathogens in patients undergoing major hepatectomy with extrahepatic bile duct resection. Surgery. 2018;163:1106-13.

12. Magiorakos AP, Srinivasan A, Carey RB, Carmeli Y, Falagas ME, Giske CG, Harbarth S, Hindler JF, Kahlmeter G, Olsson-Liljequist B, et al. Multidrugresistant, extensively drug-resistant and pandrug-resistant bacteria: an international expert proposal for interim standard definitions for acquired resistance. Clin Microbiol Infect. 2012;18:268-81.

13. Sugawara G, Yokoyama Y, Ebata T, Mizuno T, Yagi T, Ando M, Nagino M. Duration of antimicrobial prophylaxis in patients undergoing major hepatectomy with extrahepatic bile duct resection: a randomized controlled trial. Ann Surg. 2018;267:142-8.

14. Bassi C, Dervenis C, Butturini G, Fingerhut A, Yeo C, Izbicki J, Neoptolemos J, Sarr M, Traverso W, Buchler M. International Study Group on Pancreatic Fistula D: Postoperative pancreatic fistula: an international study group (ISGPF) definition. Surgery. 2005;138:8-13.

15. Dindo D, Demartines N, Clavien PA. Classification of surgical complications: a new proposal with evaluation in a cohort of 6336 patients and results of a survey. Ann Surg. 2004;240:205-13.

16. Vollmer CM Jr, Sanchez N, Gondek S, McAuliffe J, Kent TS, Christein JD, Callery MP, Pancreatic Surgery Mortality Study G. A root-cause analysis of mortality following major pancreatectomy. J Gastrointest Surg. 2012;16:89102 discussion 102-103.

17. De Pastena M, Paiella S, Marchegiani G, Malleo G, Ciprani D, Gasparini C, Secchettin E, Salvia R, Bassi C. Postoperative infections represent a major determinant of outcome after pancreaticoduodenectomy: results from a high-volume center. Surgery. 2017;162:792-801.

18. Callery MP, Pratt WB, Kent TS, Chaikof EL, Vollmer CM Jr. A prospectively validated clinical risk score accurately predicts pancreatic fistula after pancreatoduodenectomy. J Am Coll Surg. 2013;216:1-14.

19. Sugimoto M, Takahashi S, Kojima M, Kobayashi T, Gotohda N, Konishi M. In patients with a soft pancreas, a thick parenchyma, a small duct, and fatty infiltration are significant risks for pancreatic fistula after pancreaticoduodenectomy. J Gastrointest Surg. 2017;21:846-54.
20. Ngu W, Jones M, Neal CP, Dennison AR, Metcalfe MS, Garcea G Preoperative biliary drainage for distal biliary obstruction and post-operative infectious complications. ANZ J Surg. 2013;83:280-6. https://doi.org/10.1111/ j.1445-2197.2012.06296.x Epub 02012 Oct 06298.

21. Ng ZQ, Suthananthan AE, Rao $S$. Effect of preoperative biliary stenting on post-operative infectious complications in pancreaticoduodenectomy. Ann Hepatobiliary Pancreat Surg. 2017;21:212-6. https://doi.org/10.14701/ahbps. 12017.14721.14704.14212 Epub 12017 Nov 14730.

22. Nagino M, Takada T, Miyazaki M, Miyakawa S, Tsukada K, Kondo S, Furuse J, Saito H, Tsuyuguchi T, Yoshikawa T, et al. Preoperative biliary drainage for biliary tract and ampullary carcinomas. J Hepatobiliary Pancreat Surg. 2008;15:25-30.

23. Yokoyama Y, Ebata T, Igami T, Sugawara G, Nagino M. Is the enteral replacement of externally drained pancreatic juice valuable after pancreatoduodenectomy? Surg Today. 2014;44:252-9.

24. Javed AA, Wright MJ, Siddique A, Blair AB, Ding D, Burkhart RA, Makary M, Cameron JL, Narang A, Herman J, et al. Outcome of patients with borderline resectable pancreatic cancer in the contemporary era of neoadjuvant chemotherapy. J Gastrointest Surg. 2018.

25. Okamura K, Tanaka K, Miura T, Nakanishi Y, Noji T, Nakamura T, Tsuchikawa T, Okamura K, Shichinohe T, Hirano S. Randomized controlled trial of perioperative antimicrobial therapy based on the results of preoperative bile cultures in patients undergoing biliary reconstruction. J Hepatobiliary Pancreat Sci. 2017;24:382-93.

\section{Publisher's Note}

Springer Nature remains neutral with regard to jurisdictional claims in published maps and institutional affiliations.

\section{Ready to submit your research? Choose BMC and benefit from:}

- fast, convenient online submission

- thorough peer review by experienced researchers in your field

- rapid publication on acceptance

- support for research data, including large and complex data types

- gold Open Access which fosters wider collaboration and increased citations

- maximum visibility for your research: over $100 \mathrm{M}$ website views per year

At BMC, research is always in progress.

Learn more biomedcentral.com/submissions 